\section{PO-0282 POWER OF EMPOWERMENT: PARENT CONTROLLED VISITORS' BADGES TO MONITOR BEDSPACE VISITOR NUMBERS IN A PICU}

${ }^{1} \mathrm{M}$ Norridge, ${ }^{2} \mathrm{~K}$ Gallagher. ${ }^{1} \mathrm{PICU}$, Evelina London Children's Hospital, London, UK, ${ }^{2}$ Child and Adolescent Nursing, Florence Nightingale School of Nursing and Midwifery King's College London, London, UK

\subsection{6/archdischild-2014-307384.935}

Background and aims Recent audit found common practice in the UK is to restrict visitors on PICU to 2 adults, including parents, to ensure staff's safe patient access. This requires nurses to take responsibility for bed space visitors, however, this proves difficult in clinical practice for all concerned. This research explored whether empowering parents to take visitor responsibility impacted visitor numbers and therefore patient safety on PICU.

Methods The research took place on a 19 bedded tertiary PICU in the UK. Each day parents were issued two visitors badges, allocated at their discretion. Badges display day, bed number and badge number, and must be visible at all times. Twelve months post-implementation, a 3 month audit was undertaken to assess bed space adherence. Questionnaires were conducted to assess staff and parent knowledge and opinion towards the system.

Results 178 bed space observations were undertaken and 95 questionnaires completed (visitors $=53$; staff $=42$ ). In 26 observations visitors were without visible badges (15\%) and in 2 instances over two visitors were at the bed space (1\%). In one exceptional instance, end-of-life care was occurring. Questionnaire results showed $98 \%$ of staff and visitors were aware of the system, with $81 \%$ reporting it beneficial to the child and family, and $92 \%$ beneficial to the unit.

Conclusions Both staff and parents report the new system is empowering to parents, granting responsibility for their child's welfare whilst still allowing staff to monitor effectually. This research has shown that through effective interaction with parents, systems can be implemented and successfully utilised, benefitting patient safety.

\section{PO-0283 WITHDRAWN}

\section{PO-0284 USE OF SOFT TISSUE NECK RADIOGRAPHS IN PAEDIATRIC ACUTE AIRWAY OBSTRUCTIONS: CURRENT PERSPECTIVE}

'E Pouliot, ' 1 JA Gagnon, ${ }^{2} S$ Larose, ${ }^{1}$ RE Bélanger. ${ }^{1}$ Pediatric, CHU de Québec - Pavillon CHUL, Quebec City, Canada; ${ }^{2}$ Emergency, CHU de Québec - Pavillon CHUL, Quebec City, Canada

\subsection{6/archdischild-2014-307384.936}

Background Soft tissue neck radiographs (STNRs) have been recognised as a helpful tool to differentiate benign causes of acute upper airway obstructions (AUAO) from epiglottitis, retropharyngeal abscess or foreign body aspiration. Based on the frequency at which those life-threatening pathologies now occur, are STNRs still widely used and what is the impact of their clinical use?

Methodology A retrospective study was conduct. Medical files from children aged 0-17 who had a STNR between January 1st 2010 and December 31st 2011 in a mid-size Canadian university paediatric hospital were reviewed. Patients were divided in 2 groups according to the conditions clinicians first suspected and compared the STNRs' interpretations with Fisher exact test. Cases of epiglottitis and retropharyngeal abscess for the same period were reviewed.

Results Among 520 STNRs identified, 88\% intended to evaluate AUAO among children. Nearly all (99\%) took place at the emergency room, with $73 \%$ of patients presenting with triage score 3 and above, and 49\% necessitating admission. Most STNR were performed among males (67\%) aged below 5 y.o. (66\%; mode $=1$ y.o.). A life-threatening cause of AUAO was first suspected by clinicians among $40 \%$ of reviewed charts. Convincing radiologic signs of life-threatening pathologies were found in 40 children (9\%). Overall, 2 cases of epiglottitis and 8 retropharyngeal abscesses were diagnosed during the study period.

Conclusion STNR is a radiologic study that is frequently used among children. The current value of STNRs appears uncertain as few showed solid evidences that may modify how clinicians currently manage paediatric AUAO.

\section{P0-0285 IDENTIFYING RADIOLOGIC SIGNS OF LIFE-THREATENING CAUSES OF ACUTE UPPER AIRWAY OBSTRUCTION IN CHILDREN: NOT THAT EASY!}

${ }^{1}$ E Pouliot, ${ }^{1} \mathrm{JA}$ Gagnon, ${ }^{2} \mathrm{~S}$ Larose, ${ }^{3} \mathrm{~A}$ Lamarre, ${ }^{1} \mathrm{RE}$ Bélanger. ${ }^{1}$ Pediatric, CHU de Québec Pavillon CHUL, Quebec City, Canada; ${ }^{2}$ Emergency, CHU de Québec - Pavillon CHUL, Quebec City, Canada; ${ }^{3}$ Radiology, CHU de Québec - Pavillon CHUL, Quebec City, Canada

\subsection{6/archdischild-2014-307384.937}

Background Soft tissue neck radiographs (STNRs) are viewed as a helpful tool to investigate causes of acute upper airway obstructions (AUAO) among children. Some radiological findings guide clinicians identifying life-threatening causes of AUAO. Do the clinicians are skilled enough to recognise those signs?

Methods A retrospective study was conduct and the medical files from children aged 0-17 who had a STNR between January 1st2010 and December 31st 2011 in a Canadian university paediatric hospital were reviewed. Those performed in an AUAO context were analysed. Identification by clinicians of significant findings on STNRs related to life-threatening causes of AUAO were compared to radiologists' reports. Kappa coefficients were determined to describe inter-rater agreement on SNRT findings. The frequency at which SNRTs were described as technically inadequate by radiologists was also analysed.

Results Among 457 STNRs, 11\% $(\mathrm{n}=52)$ showed findings of life-threatening causes of AUAO according to clinicians, compared to $17 \%(\mathrm{n}=77)$ according to radiologists (global sensibility $=35 \%$,specificity $=93 \%$; kappa $=0.327$ ). Sensibility and specificity differed according to signs evaluated: $26 \%$ and $97 \%$, kappa $=0.27$ for swollen epiglottis/aryepiglottic oedema $(n=23$ according to radiologists); $37 \%$ and $96 \%$,kappa $=0.37$ for swelling of the retropharyngeal space ( $\mathrm{n}=38$ ); $0 \%$ and $99 \%$ kappa $=-0.01$ for decrease tracheal diameter/deviation $(n=16)$; $100 \%$ and $99 \%, \mathrm{kappa}=0.86$ for the presence of a foreign body $(\mathrm{n}=3)$. Moreover, $15 \%$ of SNRTs were described as technically inadequate by radiologists.

Conclusion Identification of life-threatening causes of AUAO on STNRs appears quite challenging for clinicians. SNRTs are technically difficult to perform among children. Importance of STNRs need to be reassessed. 